\title{
New concept in diagnostic endometrial cytology: diagnostic criteria based on composition and architecture of large tissue fragments in smears
}

\author{
ELSA SKAARLAND \\ From the Department of Pathology, The Gade Institute, University of Bergen, Norway
}

SUMMARY Routine endometrial cytology was used instead of curettage as the first step in a morphological investigation of the endometrium in patients with postmenopausal bleeding. Premenopausal women with symptoms or signs indicative of premalignant or malignant disease were also studied using this method. Patients with alarming cytological findings were further investigated with curettage.

Diagnostic criteria for endometrial cytology have not been fully established: new diagnostic criteria were used in this study, which were based on the composition and architecture of larger tissue fragments in the smears. The new criteria were especially useful for tackling diagnostic problems caused by variation in nuclear size.

Two thousand six hundred and twenty five cytological investigations were conducted over three years (January 1981 to January 1984). Adequate material for diagnosis was found in 2520 specimens $(96 \%)$. Diagnosis based on the cytology was negative-that is, not indicative of malignant or premalignant disease in 2378 cases (94\%). Follow up studies in 1984 showed no false negative results. Adenocarcinoma of the endometrium was diagnosed in 31 cases, carcinoma or carcinoma in situ of the cervix in 11 cases, and carcinoma of the ovary in four cases, all confirmed by histological investigation. Of 20 cases reported as suspected carcinoma, 12 of these were verified. The cytological diagnosis of adenomatous hyperplasia showed a low sensibility: only ten of 50 histologically controlled cases could be verified after curettage.

Many instruments for endometrial cytological sampling have been designed, and promising results from tests have been published. ${ }^{1-14}$ Endometrial cytology is, however, far from being established as a world wide method in gynaecology as cervical cytology. In fact, endometrial cytology seems only to be used in some areas with special interest in this diagnostic. ${ }^{911-1315-17}$

Endometrial cytology came into routine use in the gynaecological department at this hospital and in private practice in the region after clinical accuracy tests with different instruments. ${ }^{11} 1318$

Cytological technique has been the primary means of morphological investigation in patients with postmenopausal bleeding, as well as in premenopausal patients with symptoms or signs indicative of premalignant or malignant disease in this region since $1980 .{ }^{19} \mathrm{~A}$ negative result from the cytological

Accepted for publication 12 September 1985 investigation, together with a negative result from the clinical investigation and a negative cervical smear, is considered sufficient investigation for postmenopausal bleeding. If the cytological findings indicate that further investigation is necessary curettage with histological analysis is performed. ${ }^{19}$

As a result of the clinical tests we decided to use the Endoscann instrument (renamed Gynoscann in 1984) and the Isaacs cell sampler, as reported elsewhere. ${ }^{111318}$ The Gynoscann yielded the best results. ${ }^{19}$

The interpretation of the material was difficult. This was mainly caused by variations in the nuclear size of the epithelial cells in the smears. Reports ${ }^{20-22}$ focus on nuclear size and variation in nuclear size and shape as important diagnostic criteria for discriminating between normal, hyperplastic, and malignant conditions in the endometrium.

Morphometric measurements have previously been performed on the sampler material to test the size, 


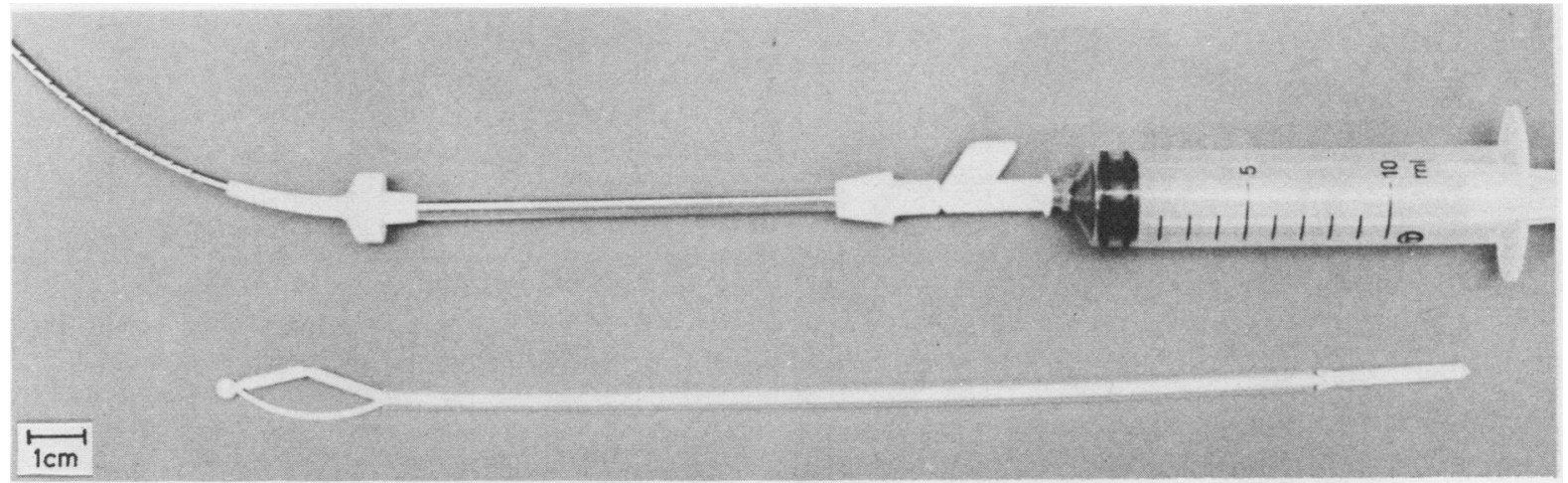

Fig. 1 Isaacs cell sampler (above) and Gynoscann instrument (below).

variation in size, and shape of the epithelial nuclei in the different conditions of the endometrium. ${ }^{2324}$ The results showed that even if there are considerable differences in the mean size of the epithelial nuclei in the different conditions, nuclear size has little importance as a diagnostic criterion because of great overlap in the recordings. ${ }^{23} 24$

New diagnostic criteria were found in the large tissue fragments in the material from the Gynoscann and the Isaacs cell sampler. The diagnostic problems were diminished when enlargements or variations in nuclear size were evaluated against the information that could be elicited from the composition, architecture, and growth pattern of the large tissue fragments.

This report describes in detail the diagnostic criteria derived from the study of large tissue fragments in the cytological samples from the endometrium and the results obtained.

\section{Material and methods}

Between January 1981 and Janary 19842625 endometrial samples were received for cytological evaluation. The material consisted of 1456 specimens sampled with the Gynoscann instrument and 1169 using the Isaac cell sampler. Indications for investigation were postmenopausal bleeding $(23 \%)$ or premenopausal symptoms or signs suggestive of premalignant or malignant disease in the endometrium $(72 \%)$. The remainder comprised asymptomatic patients screened because of previous mammary carcinoma, a combination of diabetes, hypertension, and obesity, or as a preoperative investigation (5\%). The mean age of the patients was 46 years (range 32 to 78 years).

\section{THE CYTOLOGICAL SAMPLERS}

Gynoscann This is a flexible plastic rod $23.5 \mathrm{~cm}$ long within a transparent plastic tube $17 \mathrm{~cm}$ long (Fig. 1).
The distal end of the rod is curved, forming two branches that are retracted into the tube when the instrument is introduced into the uterine cavity: the outer diameter of the instrument then becomes $3 \mathrm{~mm}$. After introduction into the uterus the rod is advanced and then rotated several times while it is moved up and down in the uterine cavity. Before extraction the rod is drawn into the sheath. The material attached to the rod is smeared on to glass slides. ${ }^{13}$

Isaacs cell sampler This is composed of a semirigid but malleable stainless steel cannula $1.9 \mathrm{~mm}$ in diameter attached to a $10 \mathrm{ml}$ syringe (Fig. 1). The cannula is slightly curved and has 40 perforations. A cervical stop ensures an airtight cervical seal after the cannula has been introduced into the cavity. Aspiration is performed under negative pressure $(400$

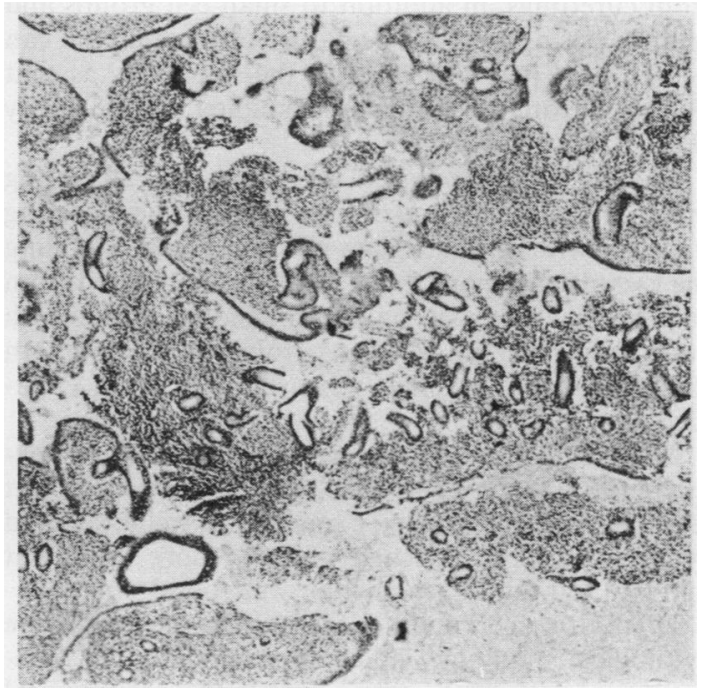

Fig. 2 Photomicrograph of histological section of material obtained from the "Gynoscann" instrument $\times 11 .$. 


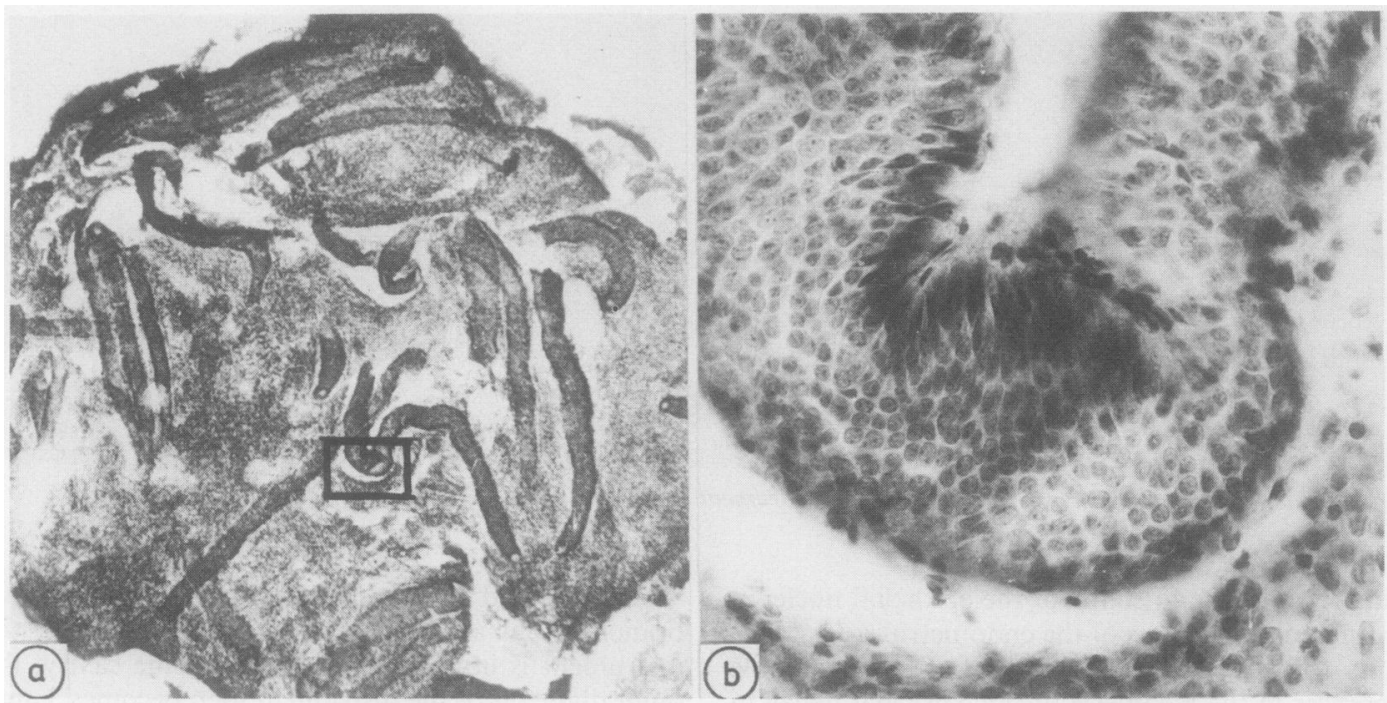

Fig. 3 Photomicrograph of tissue fragment in smear preparation showing (a) normal glands surrounded by endometrial stroma $(\times 11)$, (b) detail from the fragment (boxed area in Fig. 3a), $(\times 280)$ with curved gland and stroma. (Gynoscann smear.)

$\mathrm{mm} \mathrm{Hg}$ ) when the plunger of the syringe is withdrawn. During aspiration the cannula is moved from side to side within the uterine cavity. The material obtained from the aspiration is smeared on to glass slides. ${ }^{21}$

The material obtained from both samplers consists of pieces of endometrium, similar to those obtained from curettings, in addition to small cell groups and numerous single cells. The nature of the material can be shown if it is processed in the same way as that obtained from curettings and studied histologically (Fig. 2).

The clinicians prepared the smears by spreading material from the sampler on to a glass slide, covering the slide with another glass slide, and gently pulling the two glasses apart. Four slides were prepared from each sample. The material was immediately fixed with aerosol fixative suitable for cytological material. In the laboratory the slides were stained by the Papanicolaou method.

The cytological material was considered to be adequate for diagnosis when the material consisted of at least 30 fragments, large or small, with well preserved cytological details. Usually, much more abundant material (50 to 600 fragments) was found.

Dilatation and curettage were performed when the cytological findings indicated malignant or premalignant disease, and routine histological investigation of the curettings was performed. The histological diagnoses were recovered from the files of our department and compared with the preceding cytological findings. Follow up of the patients took place in December 1984. The files were checked for any cytological or histological investigations that had been performed after the endometrial sampling.

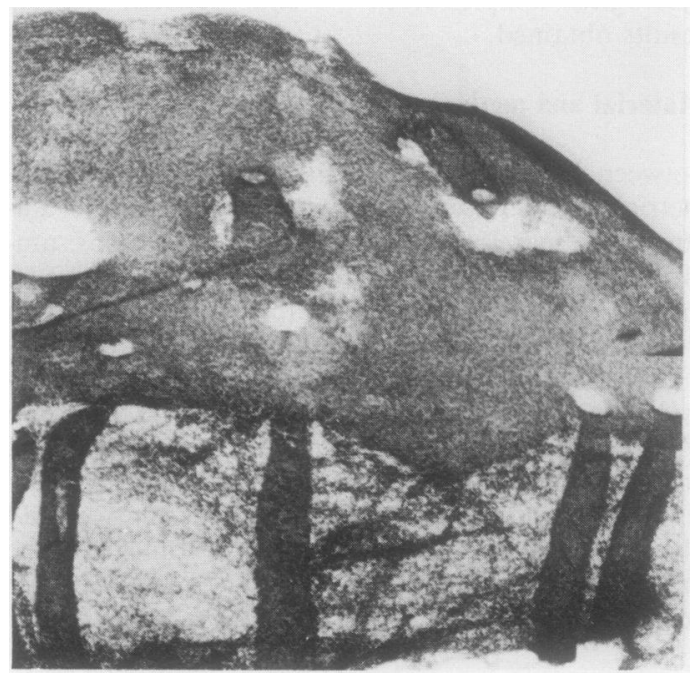

Fig. 4 Photomicrograph of tissue fragment showing sheet of surface epithelium with openings of glands, glands, and endometrial stroma. $\times 90$. (Gynoscann smear.) 
Results

\section{SAMPLER MATERIALS}

Normal conditions Smears from asymptomatic material showed large tissue fragments with glandular structures surrounded by endometrial stroma (Figs. 3a and b). Often sheets of surface epithelium were found (Fig. 4). Smaller fragments were composed of cells not readily recognised as parts of glands, surface epithelium, or stroma. Variations in nuclear size were seen from fragment to fragment, but the nuclei tended to be uniform in size within one small fragment. Variations in nuclear staining properties and nucleolar size were observed from fragment to fragment. The "background" of the smear consisted of well preserved single cells, naked nuclei, and erythrocytes without evidence of necrosis or a leucocytic reaction.

Atrophic endometrium Smears from atrophic endometrium were dominated by small sheets of surface epithelium. Tissue fragments containing glands and stroma were seldom seen. Variations in nuclear size and staining properties were evident. Sheets of cells with large nucleoli could sometimes be seen.

Malignant conditions In malignant material the smears showed tissue fragments without the normal composition of glands and endometrial stroma. Instead, the fragments were composed of colonies of cells supported by ordinary connective tissue (Figs. 5a and b). Glandular formations were seldom seen. Tissue fragments showing papillary formations were sometimes observed (Fig. 6). Variation in nuclear size, hyperchromasia, coarse chromatin, and large nucleoli could be found in the cell colonies in some of the samples. The smears from the malignant material, however, were also sometimes dominated by cells that showed little variation in size, normochromasia or hypochromasia, a chromatin pattern not dissimilar from that of normal material, and small nucleoli. The background of the smears in all the malignant cases consisted of myriads of granulocytes and small macrophages with many necrotic cells and abundant cellular debris.

Smears from cases in which material from curettings had shown adenomatous hyperplasia ${ }^{25}$ as a widespread phenomenon in the uterine cavity contained tissue fragments that were dominated by a branching system of small and larger glands (Figs. 7a, b and c) with little endometrial stroma between the glands. The glandular cells sometimes showed eosinophilic staining of the cytoplasm and pale large nuclei, but many of the glands were composed of cells that did not look dissimilar from those seen in normal material. The background showed myriads of single epithelial and stromal cells and small cell groups, without granulocytes or evidence of tissue necrosis.

No characteristic cytological appearance was found in smears from cases which had shown cystic glandular hyperplasia histologically. Occasionally, some of the tissue fragments showed tortuous, dilated glandular structures. A similar picture was found in smears from the secretion phase. The stromal compartment was not different from the stromal appearance in the proliferative phase.

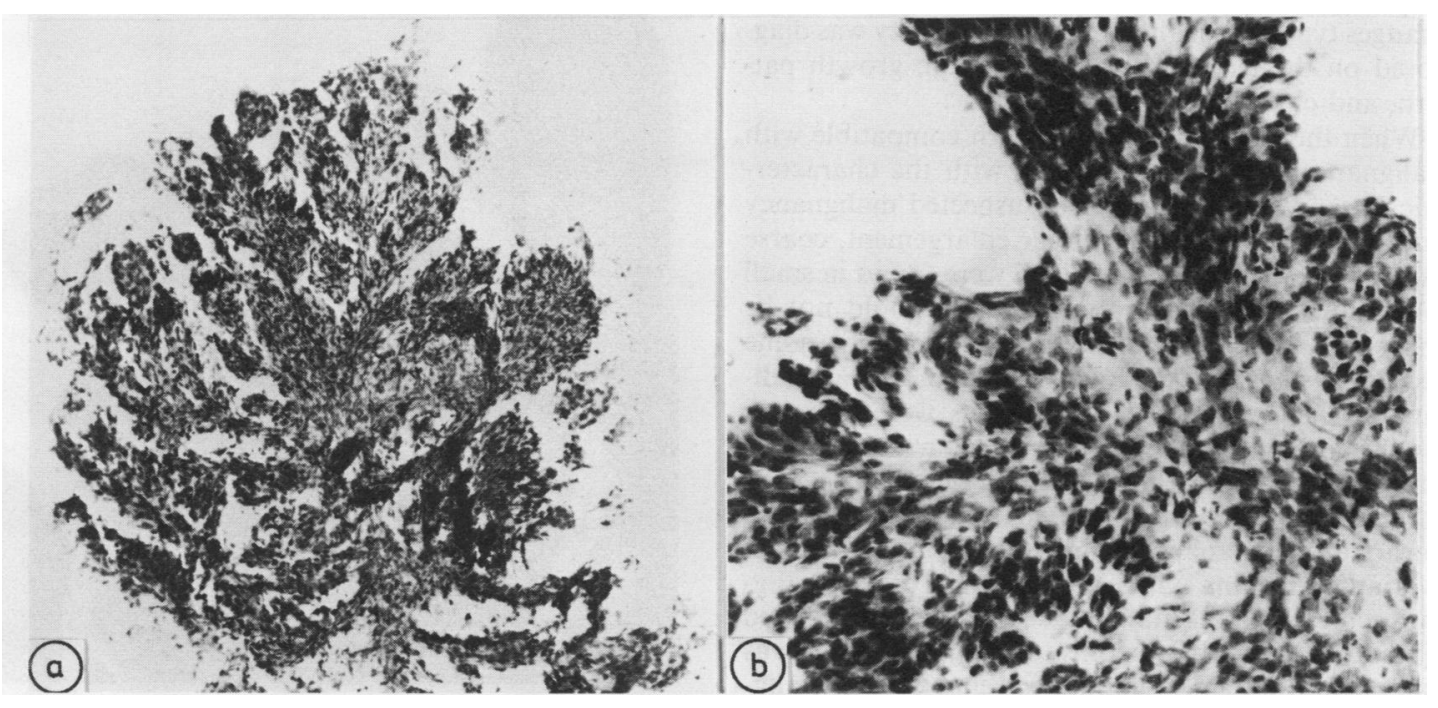

Fig. 5 (a) Photomicrograph of tissue fragment consisting of colonies of cells and connective tissue $\times 7$, (b) Photomicrograph of another fragment showing identical composition. $\times 224$. (Gynoscann smears.) 


\section{DIAGNOSTIC CRITERIA}

These criteria were based on the subjective assessment of the smears, taking into consideration the results from previously reported morphometric measurements of epithelial nuclei in smears from sampler material obtained with the same instruments. ${ }^{2324}$ The material was analysed with special reference to the composition of the larger tissue fragments. The general background of the smear was inspected, and routine screeping of the slide was performed.

The appearance of the surface and glandular epithelium and the stroma cells in the large fragments with normal anatomy (Figs. 3a, b, and Fig. 4) were compared with the appearance of the cells in smaller cell groups and single cells to decide whether the small groups represented epithelium or stroma cells and whether their appearance could be accepted as compatible with normal anatomy. Thus the cells in the large tissue fragments served as a standard for the interpretation of the smaller groups, regarding nuclear size, chromatin pattern, staining properties, and nucleolar size.

When larger tissue fragments did not show the normal architecture of glands and stroma the cell types and growth pattern in the fragments were analysed. Irregularly growing epithelial cells with fibrous connective tissue (Figs. 5a, b, and Fig. 6) indicated a malignant epithelial tumour. When the background was dominated by necrosis, large numbers of granulocytes, and small macrophages malignancy was diagnosed. When the cells in the fragments showed variation in nuclear size, coarse chromatin, hyperchromasia, and large nucleoli this supported a malignant diagnosis, but even if the cells did not show such changes typical of malignancy a malignancy was diagnosed on the basis of the composition, growth pattern, and characteristic background.

When there was a growth pattern compatible with malignancy, but not compatible with the characteristic background in the smear suspected malignancy was diagnosed. If severe nuclear enlargement, coarse chromatin, and enlarged nucleoli were found in small cell groups where the growth pattern could not be analysed, and a granulocytic reaction with some necrosis was seen suspected malignancy was indicated. When malignant looking cells were found in small clumps mixed with endometrium without malignant changes and without evidence of tissue necrosis or granulocytic reaction in the background of the smears a malignancy was diagnosed, suggesting that ovarian carcinoma could be the origin of the malignant cells. When the malignant colony of cells showed squamous differentiation only, origin in the cervix was suggested. If the smear contained cells showing malignant changes compatible with carcinoma in situ of the cervix this condition was diagnosed.
Adenomatous hyperplasia was diagnosed when large tissue fragments showed a branching system of glands with little endometrial stroma (Figs. 7a, b, and c), a background material dominated by naked nuclei derived from either the epithelial or stromal compartment, and no evidence of granulocytic reaction or tissue necrosis. During the first two years of the study attention was also paid to epithelial cells showing cellular enlargement, eosinophilic staining of the cytoplasm, and enlarged nuclei with large nucleoli. ${ }^{21}$ Suspected adenomatous hyperplasia was reported on the basis of such findings. Histological control could not confirm that these cellular changes were of any diagnostic value. In the last year of the study the criteria for adenomatous hyperplasia, therefore, were based entirely on the composition and growth pattern of fragments and the background of the smears. The criteria for atypical hyperplasia comprised a composition and cellular growth pattern compatible with malignancy, but with endometrial stroma instead of fibrous connective tissue in the fragments and without evidence of heavy granulocyte reaction or necrosis in the background of the smear.

The diagnoses were graded negative - that is, no evidence of malignant or premalignant disease; adenomatous hyperplasia or suspected adenomatous hyperplasia; atypical hyperplasia; malignant tumour with characterisation of tumour type and origin; and indication of malignant changes.

EVALUATION OF THE MATERIAL

Adequate and well preserved material was found in 2520 specimens $(96 \%)$. Endometrium without evi-

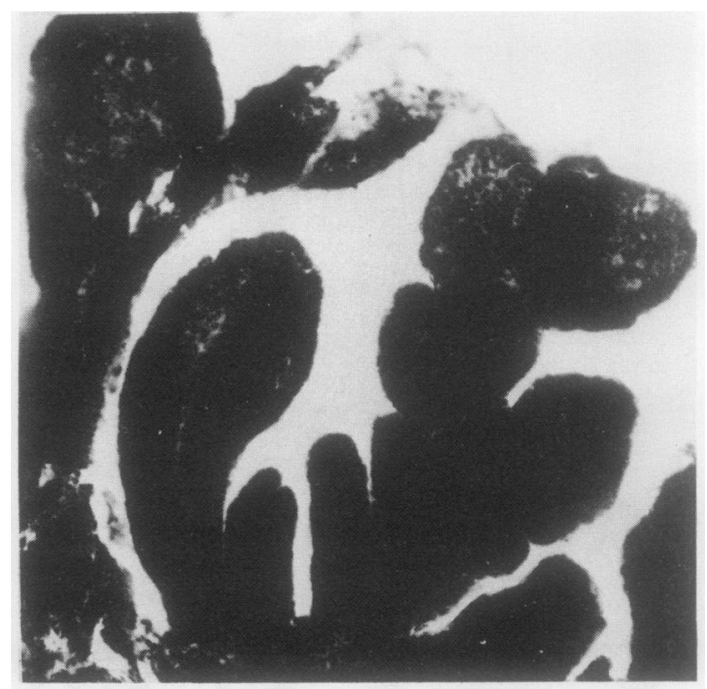

Fig. 6 Photomicrograph of thick tissue fragment showing papillary borders. $\times 112$. (Gynoscann smears.) 


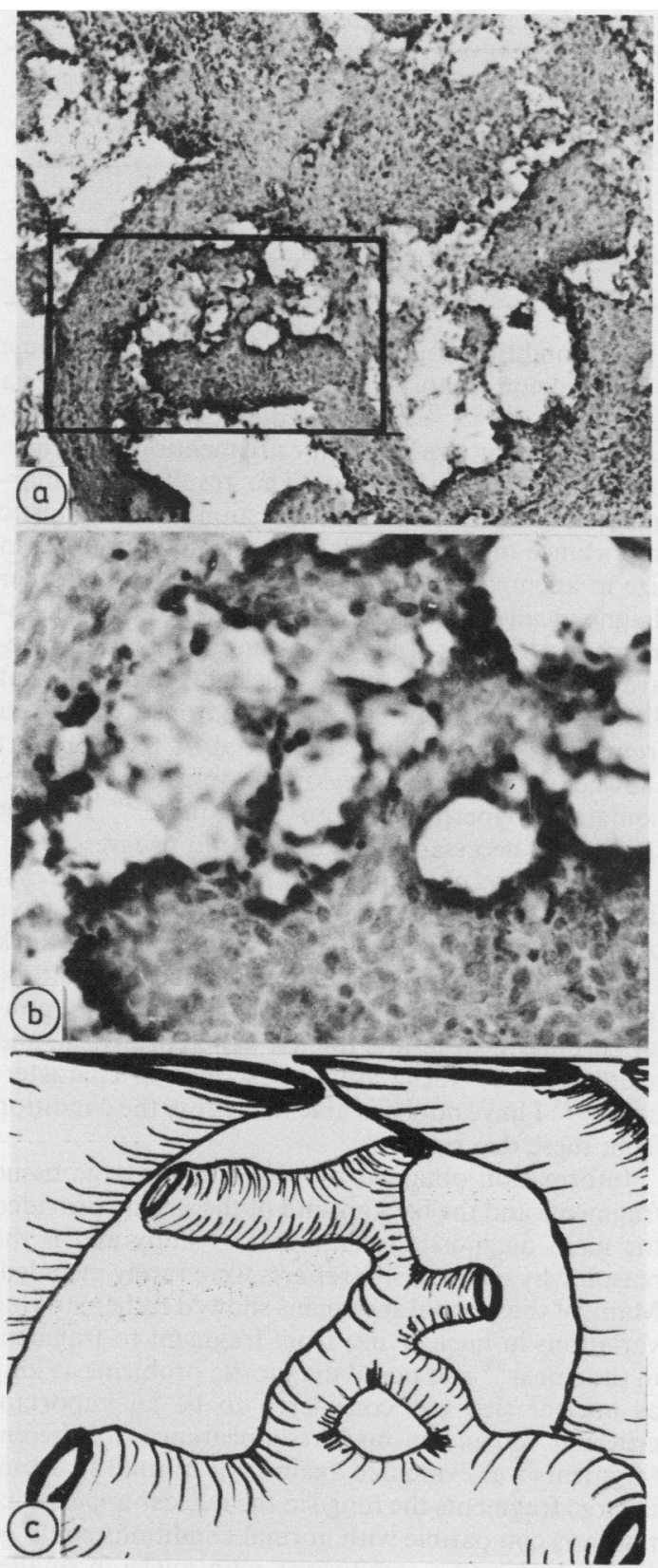

Fig. 7 (a) Photomicrograph of tissue fragment composed of anastomosing glands of varying size and little endometrial stroma $(\times 28)$; (b) detail from Fig. 6 a (boxed area in Fig. 7a) $(\times 280)$ showing glands of varying diameter growing in anastomosing pattern; (c) schematic drawing of photomicrograph in Fig. $6 b$ indicating how microscopic picture is interpreted. (Gynoscann smears.) dence of malignant or premalignant disease was found in 2378 cases. The follow up study in December 1984 did not show any patient in this group with a histological diagnosis of premalignant or malignant endometrial disease.

Of the remaining 142 cases, 46 were reported to have changes consistent with carcinoma. In all these cases the malignant diagnosis was confirmed by histology. Of these, 31 cases were diagnosed as adenocarcinoma of the endometrium and 11 cases as squamous carcinoma or carcinoma in situ of the cervix. Four cases were classified as ovarian carcinomas, a diagnosis which was confirmed by the surgical specimens.

Changes indicative of carcinoma were reported in 20 cases. Histology confirmed an adenocarcinoma of the endometrium in nine. Two patients in this group had carcinoma in situ of the cervix and proliferative endometrium, and one patient had a stromal sarcoma of the endometrium. Of the remaining eight patients, one case showed focal adenomatous hyperplasia, four, glandular cystic hyperplasia, one proliferative, and two secretory endometrium.

Adenomatous hyperplasia was presumed in 27 cases. Histological control of the diagnosis was performed in 14 cases. Four diagnoses were verified; the other ten cases showed various different conditions of the endometrium (Table). Suspected adenomatous hyperplasia was reported in 49 cases. Histological control of the diagnosis was performed in 36. Six diagnoses were verified (Table). No cases of atypical hyperplasia were diagnosed in this series.

\section{Discussion}

Women with postmenopausal bleeding are traditionally investigated with curettage and histology. Many of the premenopausal women showing symptoms indicative of malignant or premalignant disease are also investigated using this technique.

On the basis of cost analyses it has been said that diagnostic dilatation and curettage represents one of the most expensive tests in the entire field of medicine. ${ }^{26}$ Great savings can be achieved if endometrial cytology is used instead.

In this series at least 600 (all the patients with postmenopausal bleeding) and probably more than 1200 cases would have been investigated with curettage and histology if the cytological technique had not been available. Only 142 patients had to have curettage performed after cytological evaluation of the endometrium had been performed.

Provided that the cytological negative diagnoses were correct and gave the information which the clinician needed, cytological technique radically reduced the need for curettage in the assessment of pre- 
Table Correlation between cytological diagnosis of adenomatous hyperplasia and histological control

\begin{tabular}{|c|c|c|c|c|c|c|}
\hline \multirow[t]{2}{*}{ Cytological diagnoses } & \multicolumn{6}{|c|}{ Histological control } \\
\hline & $\begin{array}{l}\text { Adenomatous } \\
\text { hyperplasia }\end{array}$ & $\begin{array}{l}\text { Cystic gland } \\
\text { hyperplasia }\end{array}$ & $\begin{array}{l}\text { Proliferating } \\
\text { endometrium }\end{array}$ & $\begin{array}{l}\text { Secretory } \\
\text { endometrium }\end{array}$ & $\begin{array}{l}\text { Atrophic } \\
\text { endometrium }\end{array}$ & Others \\
\hline \multirow{2}{*}{$\begin{array}{l}\text { Adenomatous hyperplasia } \\
\text { Suspected adenomatous } \\
\text { hyperplasia }\end{array}$} & 4 & 3 & 4 & 1 & 1 & 1 \\
\hline & 6 & 4 & 10 & 5 & 5 & 6 \\
\hline Total & 10 & 7 & 14 & 6 & 6 & 7 \\
\hline
\end{tabular}

malignant and malignant endometrial disease in premenopausal women. No false negative results were found in the follow up study in 1984 . The observation time was probably sufficient to show false negative cancer results, but the follow up is of little value if potential cases of adenomatous and atypical hyperplasia have been overlooked.

The accuracy of cytological technique $v$ curettage and histological investigation has been tested by many investigators using different instruments. Most reports show satisfactory results in the detection of malignant lesions, ${ }^{9-1113151621}$ including those shown in this study.

Six patients in whom cytology reported changes indicative of malignancy could not have these results verified by histology. One of the cases entailed a patient treated with tamoxifen for mammary carcinoma. This drug has effects similar to those of oestrogen. ${ }^{27}$ The smear showed nuclear and nucleolar enlargements in epithelial cells after three months of treatment, compared with the control smear before treatment was started. No granulocyte reaction or necrosis were found. A possible effect due to drugs was mentioned in the report, but the changes were focal and severe and were reported as suspected malignancy. Another case showed numerous papillary epithelial structures in the smear and was alarming for that reason: again no granulocyte reaction or necrosis was seen. Control histology of curettings showed proliferative endometrium without evidence of papillary growth. An explanation may be that there were focal areas of papillary metaplasia ${ }^{28}$ on the surface of the endometrium not discovered by the histological control.

Variable results have been reported in the diagnosis of premalignant lesions. The accuracy of cytology in diagnosing atypical hyperplasia could not be tested in this study, but the condition has been successfully detected by cytology in previous reports: ${ }^{11} 131621$ the number of cases in these reports is small and does not allow for firm conclusions to be drawn. The results vary concerning the cytological detection of adenomatous hyperplasia, showing figures with a range from 10 to $90 \%$ agreement between cytological and histological investigations. ${ }^{1321}$ Only $20 \%$ of the cases diagnosed as adenomatous hyperplasia or indicative of this condition could be verified in this study. Some of the previous reports describe the diagnostic criteria used so far. ${ }^{162129}$ Nuclear enlargements and variation in nuclear size and shape are mentioned as char-? acteristic of the condition. The results of a mor- $\varphi$ phometric study, however, question the diagnostic $\overrightarrow{\dot{\omega}}$ importance of nuclear enlargements and variation in size in adenomatous hyperplasia, as well as in other 을 diagnostically important conditions of the endo- metrium. ${ }^{24}$ In this study it was impossible on subjective assessment to find nuclear changes that? differentiated the nuclei in adenomatous hyperplasia from those seen in normal material. A recent report showed that criteria previously described for ade- $\stackrel{\infty}{\infty}$ nomatous hyperplasia were inadequate. ${ }^{30}$ Further $\%$ studies are necessary and these are in progress. ${ }^{30}$

Descriptions of the microscopic appearance of cystic glandular hyperplasia in smear preparations have $\bar{O}$ been documented. ${ }^{162122}$ Abundant material, thick clusters, slight nuclear enlargement, nucleoli, mitotic $\stackrel{\mathbb{Q}}{\mathbb{2}}$ figures not related to proliferative phase, finely granu- $\overrightarrow{\vec{B}}$ lar chromatin structure, intense hyperchromasia, and $\stackrel{\circ}{\exists}$ overlapping of nuclei are all described as character- $\vec{P}$ istic. ${ }^{2021}$ I have not been able to identify the condition? from these descriptions.

Information obtained by studying the large tissue? fragments and the background of the smears provided $\frac{5}{3}$ the main diagnostic criteria in this study and is the reason why inconclusive reports were rarely included. Many of the normal specimens showed rather striking variations in nuclear size from fragment to fragment윽 in the smear ${ }^{23}$ and posed diagnostic problems as long $>$ as nuclear size was considered to be an important criterion. When the nuclear appearance in different $N_{0}$ fragments was evaluated against the normal structure in large fragments the range in the nuclear appearance that was compatible with normal conditions could bew established, and a comparison with nuclei in smaller? fragments could be made in the actual specimen. Ito was unnecessary to refer only to a numerical standardळ set for cytological smears.

The appearance of the tissue fragments was of great value for the diagnosis in malignant cases. Samples $\frac{\vec{\Phi}}{\mathbb{D}}$ from some of the malignant cases showed almost nor- $\Omega$ mal looking cells both in small groups and in the $\mathbb{Q}$ larger tissue fragments. The fragments, however 
showed an atypical growth pattern with papillary or solid structures and supporting connective tissue necrosis and heavy leucocytic reaction was found only in smears from patients with malignant tumours. Cases of endometritis may show a similar background, but the necrotic component is absent or far less well developed.

No reports have been written that compare the ability of the cytological technique with curettage, regarding the detection of small lesions. All the cases that proved to be malignant endometrial lesions in this study showed invasion into the myometrium.

The main role of endometrial cytology is to find patients with malignant and premalignant disease. Differential diagnoses in those smears in which the cytological findings indicated that the patient had to be investigated further were of minor interest as no final diagnostic conclusions could be drawn from the cytological report alone. The detailed morphological analysis of the state of the endometrium regarding the various conditions, ranging from adenomatous hyperplasia to invasive lesions, should be made using histological techniques.

The main problems in endometrial cytology are focused on the quality of sampling of material from premalignant focal lesions and the subsequent diagnostic problems: endometrial cytology is difficult to interpret. ${ }^{14}$ The criteria outlined in this study should be of use in interpreting malignant cases and should help to reduce the incidence of unnecessary cause for concern.

I thank the cytotechnologists of the department of pathology for their excellent screening of the slides. My sincere thanks are also due to Dr J Christensen, Professors M Farstad and F Hartveit for their help with the manuscript. I also thank T Christensen for photographic help.

\section{References}

${ }^{1}$ Papanicolaou GN, Marchetti AA. The use of endocervical and endometrial smears in the diagnosis of cancer and of other conditions of the uterus. Am J Obstet Gynecol 1943;46:421-2.

${ }^{2}$ Cary WH. A method of obtaining endometrial smears for study of their cellular content. Am J Obstet Gynecol 1943;46:422-3.

${ }^{3}$ Ayre JE. Rotating endometrial brush: new technique for the diagnosis of fundal carcinoma. Obstet Gynecol 1955;5:137-41.

${ }^{4}$ Morton DG, Moore JG, Chang N. Endometrial lavage as an aid in the diagnosis of carcinoma of the endometrium. Western Journal of Surgical Obstetrics and Gynecology 1957;65:113-9.

${ }^{5}$ Dowling EA, Gravlee LC. Endometrial cancer diagnosis: a new technique using a jet washer. Ala J Med Sci 1964;1:412-6.

${ }^{6} \mathrm{Johnsson}$ JE, Stormby NG. Cytological brush technique in malignant disease of the endometrium. Acta Obstet Gynecol Scand 1968;47:38-51.

' Milan AR, Markley RL. Endometrial cytology by a new technique. Obstet Gynecol 1973;42:469-75.
${ }^{8}$ Isaacs JH, Wilhoitte RW. Aspiration cytology of the endometrium: office and hospital sampling procedures. Obstet Gynecol 1974:118:679-87.

${ }^{9}$ Jimenez-Ayala M. Vilaplana E. Becerro de Bengoa C, et al. Endometrial and endocervical brushing technique with a Medhosa cannula. Acta Cytol 1975;19:557-63.

${ }^{10}$ Wyss R, Vassilakos P, Riotton G. Zur Fruherfassung endometrialer Veranderungen: Eine neue aspirationsmethode mit Pistolett. Geburtshilfe Frauenheilkd 1975;35:846-53.

${ }^{11}$ Segadal E, Iversen OE. The Isaacs cell sampler: an alternative to curettage. Br Med J 1980;ii:364-5.

12 Ellice RM, Morse AR, Anderson MC. Aspiration cytology versus histology in the assessment of the endometrium of women attending a menopause clinic. Br J Obstet Gynaecol 1981;88:421-5.

${ }^{13}$ Segadal E, Iversen OE. Endoscann, a new endometrial sampler. $\mathrm{Br}$ J Obstet Gynaecol 1983;90:266-71.

${ }^{14}$ Koss LG, Schreiber K, Oberlander SG, et al. Detection of endometrial carcinoma and hyperplasia in asymptomatic women. Obstet Gynecol 1984;64:1-11.

${ }^{15}$ Bibbo M, Shanklin DR, Wied GL. Endometrial cytology on jet wash material. J Reprod Med 1972;8:90-6.

${ }^{16}$ Veneti SZ, Kyrkou KA, Kittas CN, et al. Efficacy of the Isaacs endometrial cell sampler in the cytologic detection of endometrial abnormalities. Acta Cytol 1984;28:546-54.

${ }^{17}$ Koss LG, Schreiber K, Oberlander SG, et al. Screening of asymptomatic women for endometrial cancer. Obstet Gynecol 1981;57:681-91.

${ }^{18}$ Segadal E, Iversen OE, Ulstein M. Comparison of cytological jet-wash specimens and histology in endometrial carcinoma. $J$ Clin Pathol 1980;33:688-90.

${ }^{19}$ Iversen OE, Segadal E. The value of endometrial cytology. A comparative study of the Gravlee jet-washer, Isaacs cell sampler, and Endoscann versus curettage in 600 patients. Obstet Gynecol Survey 1985;40:14-20.

${ }^{20}$ Koss LG. Diagnostic cytology and its histopathologic basis. Vol 1. 3rd ed. Philadelphia: JB Lippincott Company, 1979.

${ }^{21}$ Morse AR. The value of endometrial aspiration in gynaecological practice. In: Koss LG, Coleman DV, eds. Advances in clinical cytology. London: Butterworths, 1981.

${ }^{22}$ Wied GL, Bibbo M. Cytology of endometrial jet wash samples. Chicago: Tutorials of Cytology, 1973.

${ }^{23}$ Skaarland E. Morphometric analysis of nuclei in epithelial structures from normal and neoplastic endometrium. A study using the "Isaacs cell sampler" and "Endoscann" instruments. J Clin Pathol 1985;38:496-501.

${ }^{24}$ Skaarland E. Nuclear size and shape of epithelial cells from the endometrium: lack of value as a criterion for differentiation between normal, hyperplastic, and malignant conditions. J Clin Pathol 1985;38:502-6.

${ }^{25}$ Blaustein AV. Pathology of the female genital tract. New York: Springer-Verlag, 1977:267.

${ }^{26}$ Grimes DA. Diagnostic dilatation and curettage: a reappraisal. Am J Obstet Gynecol 1982;42:1-6.

${ }^{27}$ Ferrazzi E, Cartei G, Mattarazzo R, Fiorentino M. Oestrogen like effect of tamoxifen on vaginal epithelium. $\mathrm{Br}$ Med $J$ 1977; i:1351-2.

${ }^{28}$ Silverberg SG. New aspects of endometrial carcinoma. Clin Obstet Gynecol 1984;11:191.

${ }^{29}$ Morse AR, Ellice RM, Anderson MC, Beard RW. Reliability of endometrial aspiration cytology in the assessment of endometrial status. Obstet Gynecol 1982;59:513-8.

${ }^{30}$ Meisels A, Jolicoeur C. Criteria for the cytologic assessment of hyperplasia in endometrial samples obtained by the Endopap endometrial sampler. Acta Cytol 1985;29:297-302.

Requests for reprints to: Elsa Skaarland, Department of Pathology, The Gade Institute, University of Bergen, N-5016 Haukeland Hospital, Norway. 